Research Paper

\title{
Low Expression of CDK10 Correlates with Adverse Prognosis in Gastric Carcinoma
}

\author{
Bai-wei Zhao ${ }^{1,2 \#, ~ S h i ~ C h e n ~}{ }^{1,3 \#,}$ Yuan-Fang Li ${ }^{1,2 \#, ~ J u n ~ X i a n g ~} 3$, Zhi-Wei Zhou ${ }^{1,2}$, Jun-Sheng Peng ${ }^{3,4 * \bowtie}$, Ying-bo \\ Chen ${ }^{1,2 * \otimes}$ \\ 1. The State Key Laboratory of Oncology in South China, Cancer Center, Sun Yat-Sen University, Guangzhou, China; \\ 2. Department of Gastric Surgery, Cancer Center, Sun Yat-Sen University, Guangzhou, China; \\ 3. Department of Gastrointestinal Surgery, The $6^{\text {th }}$ Affiliated Hospital, Sun Yat-Sen University, Guangzhou, China; \\ 4. Guangdong Institute of Gastroenterology, The $6^{\text {th }}$ Affiliated Hospital of Sun Yat-Sen University, Guangzhou, China. \\ \# These three authors contributed equally to this manuscript. \\ * These two authors contributed equally to this manuscript \\ $\triangle$ Corresponding authors: Ying-Bo Chen; Cancer Center, Sun Yat-Sen University, No. 651, Dongfeng Road East, 510060 Guangzhou, China. Phone: \\ +86.20.8734.3625; Fax: +86.20.8734.3625; E-mail: chenyb@sysucc.org.cn Jun-Sheng Peng; The 6 ${ }^{\text {th }}$ Affiliated Hospital, Sun Yat-Sen University, (Guangdong \\ Gastrointestinal and Anal Hospital), 26 Yuancun Erheng Road, Guangzhou, 510655, China. Phone: +86.20.38254092; Fax: +86.20.38254092; E-mail: pengjunsheng \\ @hotmail.com \\ (c) Ivyspring International Publisher. This is an open access article distributed under the terms of the Creative Commons Attribution (CC BY-NC) license \\ (https://creativecommons.org/licenses/by-nc/4.0/). See http://ivyspring.com/terms for full terms and conditions.
}

Received: 2017.03.18; Accepted: 2017.07.07; Published: 2017.08.25

\begin{abstract}
Background: Cyclin-dependent kinase (CDK) 10, is reported to play an essential role in the progression from the $\mathrm{G} 2$ to $M$ phase of the cell cycle. Recently, reduced expression of CDK10 has been observed in several cancerous human tissue, suggesting that CDK10 is a tumor suppressor gene. However, data on its expression pattern and clinical relevance in gastric cancer are not sufficient. Therefore, this study aims to investigate CDK10 expression and its prognostic significance in primary gastric adenocarcinoma.

Methodology/Principal Findings: The expression level of CDK10 was analyzed using qRT-PCR, western blotting, and immunohistochemistry on tissue samples from 189 post-resection gastric cancer patients. The expression of CDK10 mRNA was reduced in tumor tissue samples compared with matched adjacent non-tumor tissue samples $(P=0.013)$; this finding was confirmed by western blot analysis $(P=0.016)$. Immunohistochemistry data indicated that $C D K 10$ expression was significantly decreased in 92 of 189 (48.7\%) gastric cancer cases. Kaplan-Meier survival curves revealed that decreased expression of CDK10 was strongly associated with a poor prognosis in gastric cancer patients $(P<0.001)$. Multivariate Cox analysis identified CDK10 expression as an independent prognostic factor for overall survival $(P=0.011)$.

Conclusions/Significance: Our data suggest that reduced CDK10 expression independently predicts a poor prognosis in patients with gastric cancer. CDK10 can may serve as a valuable prognostic marker and a potential target for gene therapy.
\end{abstract}

Key words:

\section{Introduction}

With a total of 989,600 new cancer cases and 738,000 deaths worldwide in 2008, gastric cancer (GC) is the fourth most common malignant tumor and the second most common cause of cancer-related deaths, accounting for $10.4 \%$ of cancer-related deaths $(1,2)$. Unfortunately, in China, most gastric cancer patients are diagnosed at an advanced stage of disease, thus precluding the use of curative gastrectomy (3-5). Multidisciplinary treatment has been applied for gastric cancer patients with improved treatment outcomes in recent years (6). However, gastric cancer is still lacking efficient medicines. 
In recent decades, it has been confirmed that tumor progression of GC is a multi-step process that involves the activation of oncogenes and the inactivation of tumor suppressor genes at different stages $(7,8)$. Deregulation of cell cycle progression is considered to be critical for carcinogenesis (9). Uncontrolled cell proliferation is the hallmark of cancer, and genes that directly regulate the cell cycle are typically damaged in tumor cells (10). Endogenous regulation of the cell cycle depends on phosphorylation and dephosphorylation of the cyclincyclin-dependent kinase (CDK)-cyclin-dependent kinase inhibitor (CDKI) pathway. Recently, a series of studies revealed the diagnostic and prognostic value of CDKs (mainly CDK1-7) in different types of human cancer, including oral cancer, medulloblastoma, pancreatic cancer (11-14).

Cyclin-dependent kinase (CDK) 10 is a Cdc2-related kinase, which was first described in 1994 as PISSLRE and possesses the hallmark features common to the cyclin-dependent kinase family (15, 16). Functional studies by using both antisense and dominant-negative mutant constructs of CDK10 revealed that CDK10 plays an essential role in the progression from the G2 to M phase of the cell cycle (17). Recent studies have shown reduced expression of CDK10 in many types of cancerous human tissue, including hepatocellular carcinoma, breast cancer and biliary tract cancer, demonstrating that CDK10 is a putative new tumor suppressor gene in multiple types of human cancers (18-22). However, relatively little is known about its expression pattern, clinical relevance, and biological function in GC. Here, we estimate the expression of CDK10 in primary gastric adenocarcinoma by quantitative real-time PCR (qRT-PCR), western blotting and immunohistochemistry and evaluate its clinicopathological and prognostic value to GC patients.

\section{Material and Methods}

\section{Ethics statement}

The research was approved by the Ethics Committee of the Sun Yat-sen University Cancer Center, and written informed consent was obtained from each patient involved in the study.

\section{Patients}

From January 2005 to December 2010, clinicopathological data from 189 gastric cancer patients who underwent surgical resection at the Sun Yat-sen University Cancer Center were retrospectively analyzed. Patients who met the following eligibility criteria were included: 1) diagnosis of gastric adenocarcinoma identified by histopathological examination; 2) surgical history that included gastrectomy plus D2 lymphadenectomy; 3) availability of complete follow-up data; 4) no preoperative treatment, such as chemotherapy and radiotherapy; 5) no history of familial malignancy or other synchronous malignancy (such as GIST, esophageal cancer, or colorectal cancer); 6) no recurrent gastric cancer or remnant gastric cancer; and 7) no death in the perioperative period. Tumor resection and D2 lymphadenectomy were performed by experienced surgeons, and the surgical procedures, which followed the Japanese Gastric Cancer Association (JGCA) guidelines, were similar in all patients who underwent radical resections.

Fresh gastric cancer and adjacent non-tumor tissue samples were obtained from 48 gastric cancer patients who underwent surgical resection at the Sun Yat-sen University Cancer Center between 2012 and 2013. After surgical resection, fresh tissue samples were immediately immersed in RNAlater (Ambion, Inc., USA) and stored at $4^{\circ} \mathrm{C}$ overnight to allow thorough penetration of the tissues; the samples were then frozen at $-80^{\circ} \mathrm{C}$ until RNA extraction. Both the tumor tissue and the adjacent non-tumor tissue, which was located more than $2 \mathrm{~cm}$ away from the gastric cancer, were sampled and then verified by pathological examination. Paraffin-embedded samples were obtained from the 189 gastric cancer patients who underwent surgical resection at the Sun Yat-sen University Cancer Center between 2005 and 2010. Each tumor sample was assigned a histological grade based on the World Health Organization (WHO) classification criteria. All of the patients were staged using the 7th edition of the International Union Against Cancer (UICC) Tumor-Node-Metastasis (TNM) staging system.

\section{Extraction of total RNA and real-time quantitative PCR}

Total RNA was extracted using TRIzol (Invitrogen, Carlsbad, California, USA) according to the manufacturer's protocol. The total RNA concentration was assessed by measuring the absorbance at $260 \mathrm{~nm}$ using a NANO DROP spectrophotometer (ND-1000, Thermo Scientific, USA). Reverse transcription (RT) to synthesize the first-strand of cDNA was performed with $2 \mu \mathrm{g}$ of total RNA treated with M-MLV reverse transcriptase (Promega, USA) according to the manufacturer's recommendations. The resulting cDNA was then subjected to real-time quantitative PCR for evaluation of the relative mRNA levels of CDK10 and GAPDH (as an internal control) with the following primers:

CDK10 forward, 5'-TGGACAAGGAGAAGGAT G-3', reverse, 5'-CTGCTCACAGTAACCCATC-3'; 
GAPDH forward, 5'-CTCCTCCTGTTCGACAGTCA GC-3', and reverse: 5'-CCCAATACGACCAAATC CGTT-3'. Gene-specific amplification was performed using an ABI 7900HT real-time PCR system (Life Technologies, Carlsbad, California, USA) with $15 \mu$ of PCR mix containing $0.5 \mu l$ of cDNA, $7.5 \mu \mathrm{l}$ of $2 \times$ SYBR Green master mix (Invitrogen, Carlsbad, California, USA), and $200 \mathrm{nM}$ of the appropriate oligonucleotide primers. The mix was preheated to $95^{\circ} \mathrm{C}(10 \mathrm{~min})$ and then amplified at $95^{\circ} \mathrm{C}(30 \mathrm{sec})$ and $60^{\circ} \mathrm{C}(1 \mathrm{~min})$ for 45 cycles. The resolution curve was measured at $95^{\circ} \mathrm{C}$ for $15 \mathrm{sec}, 60^{\circ} \mathrm{C}$ for $15 \mathrm{sec}$ and $95^{\circ} \mathrm{C}$ for $15 \mathrm{sec}$. The Ct (threshold cycle) value of each sample was calculated from the threshold cycles with the instrument's software (SDS 2.3), and the relative expression levels of the target genes were normalized to the geometric mean of the internal control gene GAPDH. Each sample was tested in duplicate, and each experiment was repeated at least twice using cDNA samples from separate reverse transcription reactions. The generated data were averaged and expressed in relative units of normalized expression. The data were analyzed using the comparative threshold cycle $\left(2^{-\Delta \Delta C T}\right)$ method.

\section{Western blotting analysis}

The frozen tissue samples from patients with gastric cancer, including the tumor and non-tumor tissue, were homogenized in RIPA lysis buffer, and the lysates were cleared by centrifugation $(12,000$ $\mathrm{rpm})$ at $4^{\circ} \mathrm{C}$ for $15 \mathrm{~min}$. Approximately $40-\mathrm{mg}$ protein samples were run on $12 \%$ SDS-PAGE gels and transferred to PVDF membranes. After blocking non-specific binding sites for $60 \mathrm{~min}$ with $5 \%$ non-fat milk, the membranes were incubated overnight at $4^{\circ} \mathrm{C}$ with a primary polyclonal antibody against CDK10 (Abcam, USA, at a 1:1000 dilution). The membranes were then washed three times with TBST for $10 \mathrm{~min}$ each and probed with an HRP conjugated secondary antibody (Immunology Consultants Laboratory, USA, at a 1:2000 dilution) for $60 \mathrm{~min}$ at room temperature. The membranes were then washed three times with TBST and developed with an enhanced chemiluminescence system (ECL, Pierce).

\section{Immunohistochemistry and analysis}

The tissue sections were deparaffinized with dimethylbenzene and rehydrated through $100 \%$, 95\%, $90 \%, 80 \%$ and $70 \%$ ethanol. After three washes in phosphate-buffered saline (PBS), the slides were boiled in antigen retrieval buffer containing $0.01 \mathrm{M}$ sodium citrate-hydrochloric acid $(\mathrm{pH}=6.0)$ for $15 \mathrm{~min}$ in a microwave oven. After rinsing with PBS, the tissue sections were incubated with primary antibody, and the slides were then rinsed in a $3 \%$ peroxidase quenching solution (Invitrogen) to block endogenous peroxidases. The sections were then incubated with a mouse monoclonal antibody against CDK10 (Abcam, USA, at a 1:500 dilution) at $4^{\circ} \mathrm{C}$ overnight and then incubated with horseradish peroxidase (HRP) (ChemMateTM DAKO EnVisionTM Detection Kit) at room temperature for $30 \mathrm{~min}$. After washing in PBS, the sections were developed with 3, 3'-diaminobenzidine (DAB) solution, and all of the slides were counterstained with hematoxylin. As negative controls, adjacent sections were processed as described above, except that they were incubated overnight at $4^{\circ} \mathrm{C}$ in blocking solution without the primary antibody.

The total CDK10 immunostaining score was calculated as the sum of the percentage of positively stained tumor cells and the staining intensity. Briefly, the percentage of positive staining was scored as 0 (0-9\%, negative), 1 (10\%-25\%, sporadic), 2 (26\%-50\%, focal) or $3(51 \%-100 \%$, diffuse), and the intensity as 0 (no staining), 1 (weak staining), 2 (moderate staining) or 3 (dark staining). The total immunostaining score was calculated as the percent positivity score $x$ the staining intensity score, which ranged from 0 to 9 . The expression level of CDK10 was defined as follows: "-" (negative, score 0), "+" (weakly positive, score 1-3), "++" (positive, score 4-6), "+++" (strongly positive, score7-9). Based on the CDK10 expression levels, the gastric cancer patients were divided into two groups: a negative CDK10 expression group (CDK 10-) and a positive CDK10 expression group (CDK10+, CDK10++ and CDK10 +++).

\section{Statistical analysis}

Differences in mRNA and protein expression between tumor samples and paired adjacent non-tumor tissue samples were evaluated with paired-sample t-tests. The $\chi^{2}$ test was used to analyze the relationships between CDK10 expression and various clinicopathological parameters. Survival curves were calculated using the Kaplan-Meier method and compared by the log-rank test. A Cox proportional hazard regression model was used for univariate and multivariate analyses to study the effects of the clinicopathological variables and CDK10 expression on survival. The statistical analyses were performed with the Statistical Package for the Social Sciences, version 17.0 (SPSS Inc., Chicago, IL, USA), and a two-sided $P$ value less than 0.05 was considered statistically significant. 


\section{Results \\ CDK 10 mRNA expression analyzed with qRT-PCR}

The transcriptional levels of CDK10 were estimated by qRT-PCR assays on 48 pairs of resected specimens (tumor tissue samples and matched adjacent non-tumor tissue samples) from eligible gastric cancer patients. The CDK10 mRNA levels were significantly reduced in $29(60.4 \%)$ tumor tissue samples, compared with the adjacent non-tumor tissue samples $(P=0.013$, Figure 1$)$.

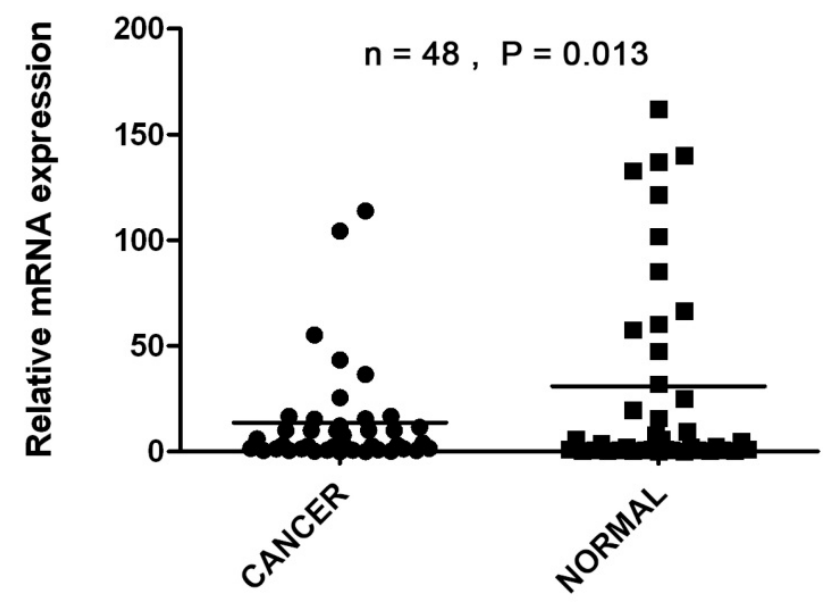

Figure 1. The CDK10 mRNA levels were significantly reduced in 29 (60.4\%) tumor tissue samples, compared with the adjacent non-tumor tissue samples by using Real-time PCR ( $P=0.013)$.

\section{CDK 10 expression analyzed by Western blotting}

CDK10 protein levels in the resected gastric cancer samples were measured by western blotting. We identified a CDK10 band at the expected size of 40 $\mathrm{kDa}$, and quantified the amount of CDK10 protein by densitometry. As shown in Figure 2, a decrease in CDK10 expression was detected in $23(57.5 \%)$ of the 40 tumor tissue samples, compared with the matched adjacent non-tumor tissue samples $(P=0.016$, Figure $2 \mathrm{~A}$ and Figure 2B). These findings were consistent with the results of qRT-PCR.

\section{The association between levels of CDK 10 expression and clinicopathological characteristics, based on immunohistochemical staining}

To obtain further insight into the effect and prognostic value of CDK10 expression in gastric cancer patients, paraffin-embedded tissue sections $(n=189)$ with histopathologically confirmed gastric adenocarcinoma were examined using immunohistochemistry. We found significant differences in CDK10 immunoreactivity between the tumor tissue and the adjacent non-tumor samples. Positive CDK10 expression was localized to the cytoplasm in $97(51.3 \%)$ tumor tissue samples, whereas the remaining 92 cases $(48.7 \%)$ displayed reduced cytoplasmic CDK10 expression (Table 1). Representative photomicrographs are shown in Figure 3. Based on the categories defined in the methods section, decreased expression of CDK10 was significantly correlated with the depth of tumor infiltration ( $\mathrm{T}$ stage, $P=0.006$ ), local lymph node metastasis ( $\mathrm{N}$ stage, $P=0.030$ ), distant metastasis $(\mathrm{M})$ $(P=0.032)$ and TNM stage $(P=0.010)$, but not with age, gender or tumor size. The result was shown in Table 1.
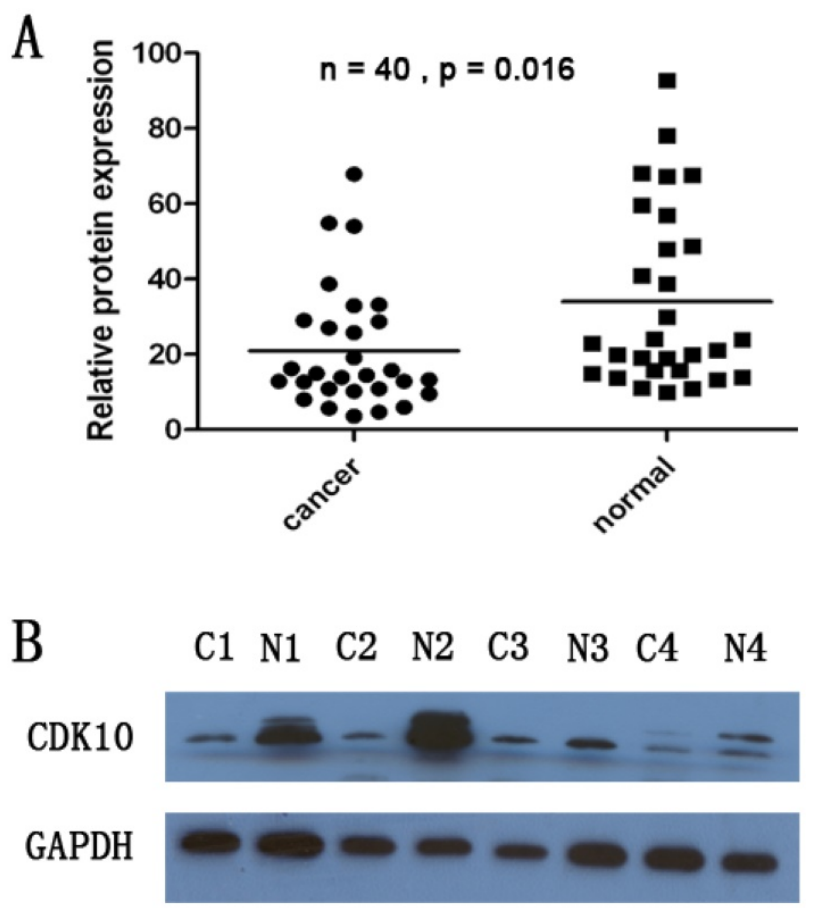

Figure 2. A decrease in CDK10 expression was detected in 23 of the 40 tumor tissue samples, compared with the matched adjacent non-tumor tissue samples by using Western -Blotting. $(\mathrm{P}=0.016)$. The band intensity was measured by densitometry using the Quantity One software. The protein levels were normalized to that of GAPDH detected using a mouse anti-human GAPDH monoclonal antibody.

\section{Expression of CDK10 and clinical outcome}

The 5-year overall survival rates in patients with high and low CDK10 expression were $66.0 \%$ and $46.7 \%$, respectively. The overall survival of patients with low CDK10 expression was significantly shorter than that of patients with high CDK10 expression $(P<0.001, \log$-rank test, Figure 4$)$. Univariate Cox regression analyses showed that the depth of tumor infiltration, local lymph node metastasis, distant metastasis, TNM stage, tumor size and CDK10 expression were significantly interrelated with overall 
survival (Table 2 and Figure 4). Furthermore, a multivariate Cox regression analysis confirmed that distant metastasis $(P<0.001)$ and CDK10 expression $(P=0.011)$ were independent predictors of overall survival in patients with gastric adenocarcinoma (Table 2).

\section{Discussion}

Tumor progression arises as a consequence of a series of cellular events, which involve deregulation of the cell cycle (22). Cell cycle progression and cell division are driven by the sequential activation of a group of serine/threonine kinases called cyclindependent kinases (CDKs) (23). In complexes that regulate the cell cycle, which consist of cyclin, CDKs and CDKIs, CDKs do not act alone; they gain their activity to trigger cell cycle progression by associating with cyclin subunits, but are negatively regulated by CDKIs (24). This delicate regulatory network ensures the precise timing and coordination of the mechanical events that duplicate and divide the cell.

Reduced expression of CDK10, which plays an essential role in the progression from the $G 2$ to $M$ phase of the cell cycle, has been shown in several types of cancerous human tissue (18-22). In our study, we found that the expression of CDK10 in tumor tissue is lower than that in adjacent non-tumor tissue according to real-time PCR, western blotting and immunohistochemistry (IHC) analyses. Furthermore, the tumor suppressor role of CDK10 was also investigated in gastric cancer cell lines.
Table 1. Correlation between CDK10 expression and clinicopathological variables of 189 gastric cancer cases

\begin{tabular}{|c|c|c|c|c|c|}
\hline \multirow{2}{*}{$\begin{array}{l}\text { Clinicopathological } \\
\text { parameters }\end{array}$} & \multirow[t]{2}{*}{$n^{\mathrm{a}}$} & \multicolumn{2}{|c|}{ CDK10 expression } & \multirow[t]{2}{*}{$x^{2}$} & \multirow[t]{2}{*}{$P$ value } \\
\hline & & Positive & Negative & & \\
\hline All & 189 & 97 & 92 & & \\
\hline \multicolumn{6}{|l|}{ Age (years) } \\
\hline$<55$ & 83 & 49 & 34 & 0.060 & 0.078 \\
\hline$\geq 55$ & 106 & 48 & 58 & & \\
\hline Gender & & & & 1.060 & 0.303 \\
\hline Male & 124 & 67 & 57 & & \\
\hline Female & 65 & 30 & 35 & & \\
\hline Tumor size & & & & 0.005 & 0.942 \\
\hline$<3 \mathrm{~cm}$ & 25 & 12 & 13 & & \\
\hline$\geq 3 \mathrm{~cm}$ & 164 & 84 & 80 & & \\
\hline Tumor infiltration & & & & 14.446 & $0.006^{*}$ \\
\hline $\mathrm{T} 1$ & 16 & 7 & 9 & & \\
\hline $\mathrm{T} 2$ & 16 & 12 & 4 & & \\
\hline $\mathrm{T} 3$ & 4 & 2 & 2 & & \\
\hline $\mathrm{T} 4 \mathrm{a}$ & 111 & 64 & 47 & & \\
\hline $\mathrm{T} 4 \mathrm{~b}$ & 42 & 12 & 30 & & \\
\hline $\begin{array}{l}\text { Local lymph node } \\
\text { metastasis }\end{array}$ & & & & 8.953 & $0.030^{*}$ \\
\hline N0 & 54 & 34 & 20 & & \\
\hline N1 & 34 & 18 & 16 & & \\
\hline $\mathrm{N} 2$ & 32 & 19 & 13 & & \\
\hline N3 & 69 & 26 & 43 & & \\
\hline Distant metastasis & & & & 4.573 & $0.032^{*}$ \\
\hline M0 & 166 & 90 & 76 & & \\
\hline M1 & 23 & 7 & 16 & & \\
\hline TNM staging & & & & 11.433 & $0.010^{*}$ \\
\hline I & 22 & 11 & 11 & & \\
\hline II & 32 & 24 & 8 & & \\
\hline III & 112 & 55 & 57 & & \\
\hline IV & 23 & 7 & 16 & & \\
\hline
\end{tabular}

${ }^{a}$ Numbers of cases in each group. ${ }^{*}$ Statistically significant $(P<0.05)$.
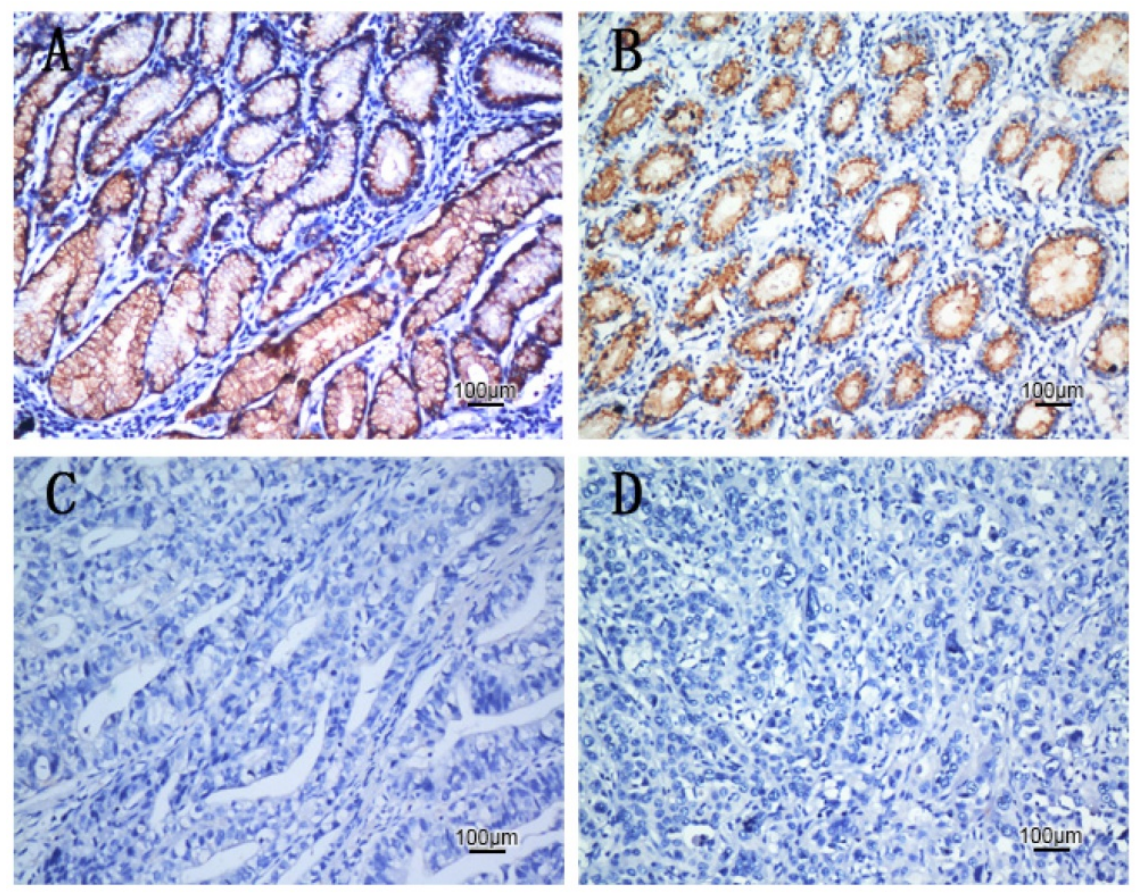

Figure 3. The expression patterns of CDK10 in gastric carcinoma tissues by IHC. A: High expressed CDK10 in gastric carcinoma tissue, scored as CDK 10(+++). B: Moderate expressed CDK10 in gastric carcinoma tissue, scored as CDK10(++). C: Slight expressed CDK10 in gastric carcinoma tissue scored as CDK10(+). D: Negative expressed CDK10 in gastric carcinoma tissue. scored as CDK10(-) 
Table 2. Kaplan-Meier univariate survival analyses and multivariate Cox regression analyses of overall survival of gastric cancer patients

\begin{tabular}{|c|c|c|c|c|c|c|c|}
\hline \multirow[t]{2}{*}{ Variables } & \multirow[t]{2}{*}{$n^{\mathrm{a}}$} & \multicolumn{3}{|l|}{ Univariate analyses } & \multicolumn{3}{|c|}{ Multivariate analyses } \\
\hline & & Mean Survival (Months) & $(95 \% \mathrm{CI})$ & $P$ value & $\mathrm{HR}$ & $(95 \% \mathrm{CI})$ & $P$ value \\
\hline Overall & & 48.168 & $44.163-52.192$ & & & & \\
\hline Age (years) & & & & 0.716 & & & \\
\hline$<55$ & 83 & 46.881 & $41.266-52.497$ & & & & \\
\hline$\geq 55$ & 106 & 47.470 & $42.069-52.871$ & & & & \\
\hline Gender & & & & 0.749 & & & \\
\hline Female & 65 & 47.321 & $40.693-53.948$ & & & & \\
\hline Male & 124 & 48.347 & $43.333-53.361$ & & & & \\
\hline Tumor size & & & & $0.012^{*}$ & & & 0.705 \\
\hline$<3 \mathrm{~cm}$ & 25 & 63.296 & $55.135-71.457$ & & 1.000 & & \\
\hline$\geq 3 \mathrm{~cm}$ & 164 & 45.335 & $41.048-49.623$ & & 0.817 & $0.287-2.328$ & \\
\hline Tumor infiltration & & & & $0.005^{*}$ & & & 0.394 \\
\hline $\mathrm{T} 1$ & 16 & \# & \# & & 1.000 & & \\
\hline $\mathrm{T} 2$ & 16 & 64.500 & $56.045-72.955$ & & $<0.001$ & $0.000-4.95 \mathrm{E} 268$ & \\
\hline T3 & 4 & \# & \# & & 0.233 & 0.053-1.029 & \\
\hline T4a & 111 & 45.664 & $40.639-50.689$ & & 0.465 & $0.267-0.853$ & \\
\hline $\mathrm{T} 4 \mathrm{~b}$ & 42 & 31.564 & 3.821 & & 0.763 & $0.471-1.238$ & \\
\hline Local lymph node metastasis & & & & $<0.001^{*}$ & & & 0.081 \\
\hline No & 54 & 61.410 & $55.366-67.454$ & & 1.000 & & \\
\hline N1 & 34 & 48.543 & $39.843-57.244$ & & 0.494 & $0.236-0.922$ & \\
\hline N2 & 32 & 47.641 & $39.079-56.202$ & & 0.540 & $0.249-1.003$ & \\
\hline N3 & 69 & 34.614 & $28.364-40.864$ & & 0.620 & $0.331-1.161$ & \\
\hline Distant metastasis & & & & $<0.001^{*}$ & & & $<0.001^{*}$ \\
\hline M0 & 166 & 52.059 & $47.986-56.133$ & & 1.000 & & \\
\hline M1 & 23 & 17.696 & $11.166-24.225$ & & 4.361 & $2.589-7.345$ & \\
\hline TNM staging & & & & $<0.001^{*}$ & & & \\
\hline I & 22 & \# & \# & & & & \\
\hline II & 32 & 55.344 & $48.062-62.625$ & & & & \\
\hline III & 112 & 44.441 & $39.562-49.319$ & & & & \\
\hline IV & 23 & 17.696 & $11.166-24.225$ & & & & \\
\hline CDK10 & & & & $<0.001^{*}$ & & & $0.011^{*}$ \\
\hline Positive & 97 & 54.461 & $49.431-59.491$ & & 1.000 & & \\
\hline Negative & 92 & 40.912 & $34.954-46.870$ & & 0.561 & $0.360-0.877$ & \\
\hline
\end{tabular}

We found that CDK10 expression is lower at both the transcriptional and translational levels in tumor tissue than in adjacent non-tumor tissue. According to IHC, 92 out of 189 cases (48.7\%) displayed reduced cytoplasmic CDK10 expression in tumor tissue. Overall, we found that CDK10 expression is reduced or lost in a number of cancer tissues, which is consistent with previous reports on hepatocellular carcinoma, breast cancer and biliary tract cancer.

Furthermore, we found that the decreased expression of CDK10 was significantly correlated with the depth of tumor infiltration (T stage, $P=0.006$ ), local lymph node metastasis ( $\mathrm{N}$ stage, $P=0.030$ ), distant metastasis $(\mathrm{M})(P=0.032)$ and TNM stage $(P=0.010)$, but not with age, gender or tumor size. In the Kaplan-Meier analysis, CDK10 expression was significantly correlated with overall survival. Multivariate Cox regression analysis confirmed that CDK10 expression $(P=0.011)$ was an independent predictor of the overall survival of patients with gastric adenocarcinoma. This is the first time that CDK10 expression was found to be an independent prognostic factor in gastric cancer. Moreover, similar findings were also reported in biliary tract cancer and hepatocellular carcinoma. Taken together, our results demonstrate that CDK10 might serve as a valuable prognostic biomarker and a potential target for future cancer diagnosis and treatments.

Crawford et al. first demonstrated that CDK10 contains a PSTAIRE-like motif named PISSLRE, which is most closely related to p58/GTA, the galactosyl transferase associated protein. PISSLRE plays an unexpected role compared with other CDKs, because it acts as an antiproliferative factor (18). Human Cdk10 maps to a region of chromosome 16 (16q24), and high rates of $\mathrm{LOH}$ and hypermethylation have been demonstrated in the promoter region of the CDK10 gene in HCC cell lines (19). Iorns et al. investigated the molecular mechanism of CDK10 in breast cancer. They found that CDK10 inactivated the c-RAF/MAPK pathway and was an important determinant of resistance to endocrine therapy for breast cancer (24). CDK10 may play similar roles in GC (25). Further understanding of the molecular mechanisms of CDK10 in GC progression is needed to establish the relationship between CDK10 and drug-resistance, which may be important for chemotherapy $(26,27)$. 

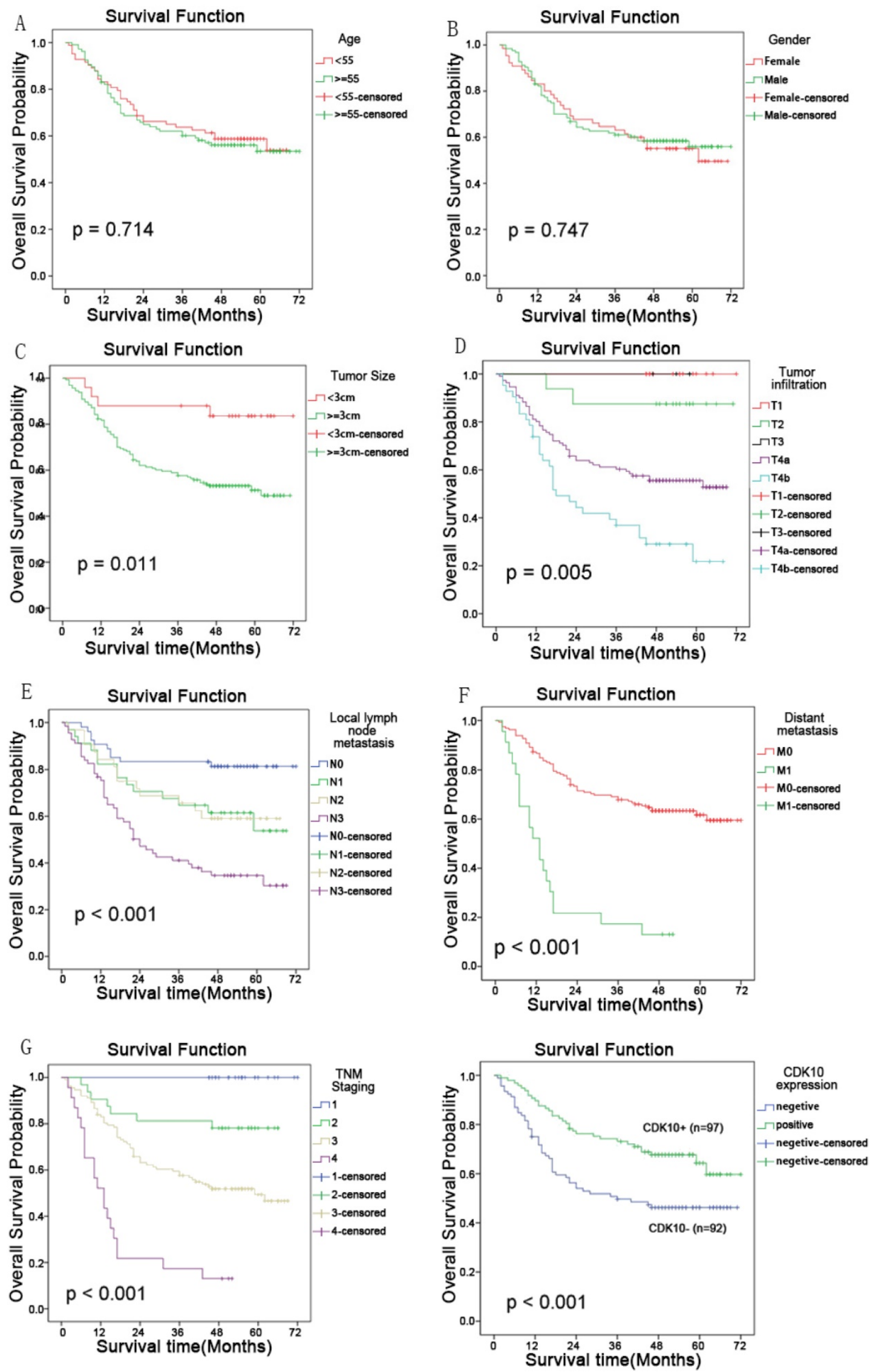

Figure 4. Kaplan-Meier analyses showed that tumor size $(P=0.0011)$; the depth of tumor infiltration $(P=0.005)$, local lymph node metastasis $(P<0.001)$, distant metastasis $(P<0.001)$, TNM stage $(P<0.001)$, and $C D K 10(P<0.001)$ expression were significantly interrelated with overall survival. But the age and gender has no correlation with the prognosis of the patients. 
In conclusion, the present study suggests that CDK10 may function as a prognostic marker in gastric cancer and low CDK10 expression independently predicts poorer overall survival in patients. However, the molecular mechanisms involved in the regulation of CDK10 in gastric cancer require further investigation. Moreover, we expect that CDK10, which directly regulates the cell cycle and may participate in other pathways, will become a useful target for new therapeutic interventions against gastric cancer.

\section{Abbreviations}

GC, gastric carcinoma; IHC, immunohistochemistry.

\section{Acknowledgements}

We thank Chen Chen from the National University of Singapore for their critical reading.

This study was supported by the Guangdong Medical Research Foundation (A2015124).

\section{Competing Interests}

The authors have declared that no competing interest exists.

\section{References}

1. Ferlay J SH, Bray F, Forman D, Mathers C, Parkin DM. Cancer incidence and mortality worldwide: GLOBOCAN 2008 v2.0. . Lyon, France: International Agency for Research. 2010 Jan 1.

2. Jemal A, Siegel R, Ward E, Hao Y, Xu J, Thun MJ. Cancer statistics, 2009. CA: a cancer journal for clinicians. 2009 Jul-Aug;59(4):225-49. PubMed PMID: 19474385.

3. Wang W, Li YF, Sun XW, Chen YB, Li W, Xu DZ, et al. Prognosis of 980 patients with gastric cancer after surgical resection. Chinese journal of cancer. 2010 Nov;29(11):923-30. PubMed PMID: 20979691.

4. Wei WQ, Yang CX, Lu SH, Yang J, Li BY, Lian SY, et al. Cost-benefit analysis of screening for esophageal and gastric cardiac cancer. Chinese journal of cancer. 2011 Mar;30(3):213-8. PubMed PMID: 21352699. Pubmed Central PMCID: 4013318.

5. Chen W, Zheng R, Zeng H, Zhang S. The updated incidences and mortalities of major cancers in China, 2011. Chinese journal of cancer. 2015 Sep 14;34(11):502-7. PubMed PMID: 26370301. Pubmed Central PMCID: 4593358.

6. Sun W, Yan L. Gastric cancer: current and evolving treatment landscape. Chinese journal of cancer. 2016 Aug 31;35(1):83. PubMed PMID: 27581465. Pubmed Central PMCID: 5006607.

7. Chen CN, Lin JJ, Chen JJ, Lee PH, Yang CY, Kuo ML, et al. Gene expression profile predicts patient survival of gastric cancer after surgical resection. Journal of clinical oncology : official journal of the American Society of Clinical Oncology. 2005 Oct 10;23(29):7286-95. PubMed PMID: 16145069.

8. Peddanna N, Holt S, Verma RS. Genetics of gastric cancer. Anticancer research. 1995 Sep-Oct;15(5B):2055-64. PubMed PMID: 8572602.

9. Evan GI, Vousden KH. Proliferation, cell cycle and apoptosis in cancer. Nature. 2001 May 17;411(6835):342-8. PubMed PMID: 11357141.

10. Sherr CJ. Cancer cell cycles. Science. 1996 Dec 06;274(5293):1672-7. PubMed PMID: 8939849

11. Mihara M, Shintani S, Nakahara Y, Kiyota A, Ueyama Y, Matsumura T, et al. Overexpression of CDK2 is a prognostic indicator of oral cancer progression. Japanese journal of cancer research : Gann. 2001 Mar;92(3):352-60. PubMed PMID: 11267947.

12. Klausen P, Bjerregaard MD, Borregaard N, Cowland JB. End-stage differentiation of neutrophil granulocytes in vivo is accompanied by up-regulation of p27kip1 and down-regulation of CDK2, CDK4, and CDK6. Journal of leukocyte biology. 2004 Mar;75(3):569-78. PubMed PMID: 14694185.

13. Mendrzyk F, Radlwimmer B, Joos S, Kokocinski F, Benner A, Stange DE, et al. Genomic and protein expression profiling identifies CDK6 as novel independent prognostic marker in medulloblastoma. Journal of clinical oncology : official journal of the American Society of Clinical Oncology. 2005 Dec 01;23(34):8853-62. PubMed PMID: 16314645.

14. Retzer-Lidl M, Schmid RM, Schneider G. Inhibition of CDK4 impairs proliferation of pancreatic cancer cells and sensitizes towards TRAIL-induced apoptosis via downregulation of survivin. International journal of cancer. 2007 Jul 01;121(1):66-75. PubMed PMID: 17304504.

15. Grana X, Claudio PP, De Luca A, Sang N, Giordano A. PISSLRE, a human novel CDC2-related protein kinase. Oncogene. 1994 Jul;9(7):2097-103. PubMed PMID: 8208557.

16. Brambilla R, Draetta G. Molecular cloning of PISSLRE, a novel putative member of the cdk family of protein serine/threonine kinases. Oncogene. 1994 Oct;9(10):3037-41. PubMed PMID: 8084611.

17. Li S, MacLachlan TK, De Luca A, Claudio PP, Condorelli G, Giordano A. The cdc-2-related kinase, PISSLRE, is essential for cell growth and acts in G2 phase of the cell cycle. Cancer research. 1995 Sep 15;55(18):3992-5. PubMed PMID: 7664269.

18. Crawford J, Ianzano L, Savino M, Whitmore S, Cleton-Jansen AM, Settasatian $\mathrm{C}$, et al. The PISSLRE gene: structure, exon skipping, and exclusion as tumor suppressor in breast cancer. Genomics. 1999 Feb 15;56(1):90-7. PubMed PMID: 10036189.

19. Riou P, Saffroy R, Comoy J, Gross-Goupil M, Thiery JP, Emile JF, et al. Investigation in liver tissues and cell lines of the transcription of 13 genes mapping to the 16q24 region that are frequently deleted in hepatocellular carcinoma. Clinical cancer research : an official journal of the American Association for Cancer Research. 2002 Oct;8(10):3178-86. PubMed PMID: 12374686 .

20. Zhong XY, Xu XX, Yu JH, Jiang GX, Yu Y, Tai S, et al. Clinical and biological significance of Cdk10 in hepatocellular carcinoma. Gene. 2012 Apr 25;498(1):68-74. PubMed PMID: 22326270.

21. Yu JH, Zhong XY, Zhang WG, Wang ZD, Dong Q, Tai S, et al. CDK10 functions as a tumor suppressor gene and regulates survivability of biliary tract cancer cells. Oncology reports. 2012 Apr;27(4):1266-76. PubMed PMID: 22209942. Pubmed Central PMCID: 3583593.

22. Hanahan D, Weinberg RA. The hallmarks of cancer. Cell. 2000 Jan 07;100(1):57-70. PubMed PMID: 10647931.

23. Santamaria D, Ortega S. Cyclins and CDKS in development and cancer: lessons from genetically modified mice. Frontiers in bioscience : a journal and virtual library. 2006 Jan 01;11:1164-88. PubMed PMID: 16146805.

24. Iorns E, Turner NC, Elliott R, Syed N, Garrone O, Gasco M, et al. Identification of CDK10 as an important determinant of resistance to endocrine therapy for breast cancer. Cancer cell. 2008 Feb;13(2):91-104. PubMed PMID: 18242510.

25. Shimizu K, Nakatsu Y, Oh-uchida M, Nomoto S, Sekiguchi M. [Activated c-raf-1 gene from human stomach cancer]. Gan to kagaku ryoho Cancer \& chemotherapy. 1987 Jun;14(6 Pt 2):2140-6. PubMed PMID: 3300556.

26. Lee HS, Cho SB, Lee HE, Kim MA, Kim JH, Park DJ, et al. Protein expression profiling and molecular classification of gastric cancer by the tissue array method. Clinical cancer research : an official journal of the American Association for Cancer Research. 2007 Jul 15;13(14):4154-63. PubMed PMID: 17634543.

27. Oue N, Hamai Y, Mitani Y, Matsumura S, Oshimo Y, Aung PP, et al. Gene expression profile of gastric carcinoma: identification of genes and tags potentially involved in invasion, metastasis, and carcinogenesis by serial analysis of gene expression. Cancer research. 2004 Apr 01;64(7):2397-405. PubMed PMID: 15059891. 